\title{
Epigenetic silencing of tumor suppressor miR-3151 contributes to Chinese chronic Iymphocytic leukemia by constitutive activation of MADD/ERK and PIK3R2/AKT signaling pathways
}

\author{
Lu Qian Wang ${ }^{1}$, Kwan Yeung Wong ${ }^{1}$, Anders Rosèn ${ }^{2}$, Chor Sang Chim ${ }^{1}$ \\ ${ }^{1}$ Department of Medicine, Queen Mary Hospital, The University of Hong Kong, Hong Kong \\ ${ }^{2}$ Department of Clinical and Experimental Medicine, Linköping University, Linköping, Sweden
}

Correspondence to: Chor Sang Chim, e-mail: jcschim@hku.hk

Keywords: microRNA, miR-3151, tumor suppressor, DNA methylation, chronic lymphocytic leukemia

Received: August 16, 2015

Accepted: October 14, 2015

Published: October 27, 2015

\section{ABSTRACT}

We hypothesize that miR-3151, localized to a GWAS-identified chronic lymphocytic leukemia (CLL) risk locus (8q22.3), is a tumor suppressor miRNA silenced by promoter DNA methylation in CLL. The promoter of miR-3151 was methylated in $5 / 7(71 \%)$ CLL cell lines, 30/98 (31\%) diagnostic primary samples, but not normal controls. Methylation of miR-3151 correlated inversely with expression. Treatment with 5-Aza-2'-deoxycytidine led to promoter demethylation and miR-3151 re-expression. Luciferase assay confirmed MAP-kinase activating death domain (MADD) and phosphoinositide-3-kinase, regulatory subunit 2 (PIK3R2) as direct targets of miR-3151. Moreover, restoration of miR-3151 resulted in inhibition of cellular proliferation and enhanced apoptosis, repression of MADD and PIK3R2, downregulation of MEK/ERK and PI3K/AKT signaling, and repression of MCL1. Lastly, miR-3151 methylation was significantly associated with methylation of $m i R-203$ and $m i R-34 b / c$ in primary CLL samples. Therefore, this study showed that $m i R-3151$ is a tumor suppressive miRNA frequently hypermethylated and hence silenced in CLL. miR-3151 silencing by DNA methylation protected CLL cells from apoptosis through over-expression of its direct targets MADD and PIK3R2, hence constitutive activation of MEK/ERK and PI3K/AKT signaling respectively, and consequently over-expression of MCL1.

\section{INTRODUCTION}

B-cell chronic lymphocytic leukemia (CLL), the most common blood cancer in the Western countries, is characterized by accumulation of neoplastic, small B lymphocytes expressing CD5, CD19 and CD23 in bone marrow, peripheral blood and other lymphoid tissues [1]. CLL cells are protected from apoptosis by autocrine proliferation signals and survival stimuli from the microenvironment $[2,3]$. It is well known that B-cell receptor (BCR) signaling is important in CLL pathophysiology, resulting in constitutive activation of downstream survival pathways including PI3K/AKT, MEK/ERK or NF- $\kappa B$ pathways, thereby protecting CLL cells from apoptosis, and hence have been exploited as targets for molecular therapies $[4,5]$.

DNA methylation refers to the addition of a methyl group (-CH3) to the carbon 5 of the cytosine ring, leading to the formation of 5-methylcytosine [6]. Many human cancers are characterized by a global DNA hypomethylation and aberrant, gene-specific DNA hypermethylation of tumor suppressor genes (TSGs) [7]. To date, numerous TSGs involved in the dysregulation of signaling pathways, including SHP1 and SOCS1 regulating JAK/STAT signaling, soluble $W N T$ inhibitors regulating WNT signaling and $C D K N 2 A$ and $C D K N 2 B$ regulating the cell-cycle, have been found to be hypermethylated in multiple hematological cancers [8-10]. Of note, recent studies have identified methylation of additional TSGs including DAPK1, ID4 and SFRP1, which are implicated in the pathogenesis or prognosis of CLL [11-13]. microRNAs (miRNAs) have been discovered as a class of single-stranded, non-protein-coding small RNAs of 19 to 25 nucleotides in length. miRNAs regulate expression of protein-coding genes by binding to specific seed region binding site on $3^{\prime}$ untranslated region (3'UTR) 
of the target mRNAs, leading to translational repression or mRNA degradation of the target genes [14]. miRNAs involved in CLL may be oncogenic or tumor suppressive. Recently, a miRNA signature comprising 18 putative oncogenic miRNAs and seven putative tumor suppressor miRNAs has been identified in CLL by comparing CLL cells with normal B cells [15]. An alternative mechanism of miRNA silencing in cancer is DNA methylation of promoter-associated $\mathrm{CpG}$ island. Indeed, methylation silencing of tumor suppressor miRNAs including $m i R-203, m i R-124-1, m i R-34 b / c$, and $m i R-9-3$ have been demonstrated in CLL, hence implicated in CLL leukemogenesis [16-19].

Recently, the updated GWAS meta-analysis, which included a total of 3,100 individuals with CLL cases and 7,667 controls, identified 12 new CLL susceptibility loci, some of which harbor apoptosis-regulating tumor suppressor genes (such as BIM,NOXA) downregulated in CLL [20]. These finding prompted us to postulate that tumor suppressive miRNAs might be present in the neighborhood of these susceptibility loci, and their expression silenced by DNA hypermethylation. Interestingly, bioinformatics analysis showed that $m i R-3151$, with a promoter-associated $\mathrm{CpG}$ island, is localized to intron 1 of the brain and acute leukemia cytoplasmic $(B A A L C)$ gene at $8 \mathrm{q} 22.3$, one of the GWAS-identified risk loci. Herein, we studied $m i R-3151$ methylation in a representative cohort to define its role in CLL pathogenesis.

\section{RESULTS}

\section{MSP of miR-3151 in normal controls and CLL cell lines}

As illustrated in the schematic diagram showing the promoter region of $m i R-3151$ and its host gene $B A A L C$ (Supplementary Figure S1A), methylation of the promoter of $m i R-3151$ was studied by MSP and bisulfite pyrosequencing using primers designed at the $\mathrm{CpG}$ island upstream to the transcription start site (TSS). None of the 9 healthy donor samples (N1 to N9) showed aberrant methylation of miR-3151 (Figure 1A). Direct sequencing analysis of the miR-3151 M-MSP products from a bisulfitetreated methylation positive control showed expected conversion of unmethylated cytosine to thymidine after PCR (but not methylated cytosine), indicating complete bisulfite conversion and MSP specificity (Figure 1B). Moreover, in CLL cell lines, WAC3CD5+ revealed complete methylation, MEC1, 232B4, HG3 and I83-E95 showed partial methylation, whereas MEC2 and CLL-AAT displayed complete unmethylation of $m i R-3151$ (Figure 1C). Quantitative bisulfite pyrosequencing validated the MSP methylation statuses (MM, MU, UU) of the CLL cell lines (Supplementary Figure S2). In addition, the mean expression of $m i R-3151$ in methylated CLL cell lines was significantly lower than that in unmethylated cell lines, and hence a higher $\Delta \mathrm{Ct}(\Delta \mathrm{Ct} m i R-3151-\Delta \mathrm{Ct} R N U 48)$ $(P=0.01)$ (Figure 1D).

To examine if the expression of $m i R-3151$ correlated to that of its host gene $B A A L C$ in CLL, the expression of $B A A L C$ was studied by qRT-PCR using Taqman assay in seven CLL cell lines. Results showed that the expression of $B A A L C$ in partially methylated cell lines (MEC1, 232B4, HG3 and I83-E95) was significantly lower than that of completely unmethylated CLL cell lines (MEC2 and CLL-AAT) $(P=0.05)$ (Supplementary Figure S1B), as indicated by a higher $\triangle \mathrm{Ct}(\mathrm{Ct} B A A L C-\mathrm{Ct} G A P D H)$ in partially methylated than completely unmethylated CLL cell lines. Therefore, expression of $m i R-3151$ was correlated with that of its host gene $B A A L C$ in most CLL cell lines, except the completely methylated cell line (WAC3CD5+ cells).

\section{MSP of $m i R-3151$ in CLL primary samples at diagnosis}

Methylation of $m i R-3151$ was detected in 30/98 (31\%) of primary samples at diagnosis (Figure 2A). Importantly, in 20 samples with both DNA and RNA, methylation of $m i R-3151(N=6)$ was associated with lower $m i R-3151$ expression than those without $m i R-3151$ methylation $(N=14, P=0.04)$ (Figure $2 \mathrm{~B})$. There was no significant correlation between $m i R-3151$ methylation and the diagnostic lymphocyte count, hemoglobin level, platelet count, age, gender or high-risk karyotypes. The median OS of CLL patients with and without miR-3151 methylation were 89 and 69 months respectively $(P=0.65)$. Among the 98 samples, concomitant methylation study of $m i R-3151$ with $m i R-203$ was performed in 50 patients, $m i R-34 \mathrm{~b} / \mathrm{c}$ in 78 patients, and $m i R-34 a$ in 78 primary CLL samples respectively. The data for methylation of each of $m i R-203, m i R-34 b / c$ or $m i R-34 a$ have been published previously $[16,18]$. Of these, five (10\%) patients showed concomitant methylation of miR-203 and miR-3151 $(P=0.002), 10(13 \%)$ patients concomitant methylation of $m i R-34 \mathrm{~b} / \mathrm{c}$ and $m i R-3151$ $(P=0.001)$, and two $(2.6 \%)$ patients concomitant methylation of $m i R-34 a$ and $m i R-3151(P=0.07)$.

\section{5-AzadC treatment of WAC3CD5+ and MEC2 cells}

To test if promoter methylation led to downregulated expression of $m i R-3151$, both CLL cell lines completely methylated (WAC3CD5+) and completely unmethylated (MEC2) for miR-3151 were independently treated with a hypomethylating agent. Treatment with 5-AzadC in WAC3CD5+ cells led to promoter demethylation as evidenced by the emergence of U-MSP signal, and hence, with a corresponding increase of $m i R-3151$ and $B A A L C$ expression on Day 7 (Figure 3A, Supplementary Figure $\mathrm{S} 1 \mathrm{C}$ and Figure S2C). By contrast, treatment with 5-AzadC 
in MEC2 cells did not render a change in the methylation status and expression of miR-3151 (Figure 3B).

\section{Effect of $m i R-3151$ over-expression in WAC3CD5+ cells}

As $m i R-3151$ is frequently methylated and underexpressed in CLL cell lines and primary samples, we postulated that it might act as a tumor suppressive miRNA, and hence investigated tumor suppressor function of miR-3151 in CLL cells in vitro. By TaqMan stem-loop quantitative RT-PCR, over-expression of $m i R-3151$ was shown to be induced in WAC3CD5+ cells 48 hours after transfection (Figure 4A). Overexpression of $m i R-3151$ led to a $20 \%$ reduction of cell proliferation as measured by MTT assay $(P=0.04$, Figure 4B), an addition of $12 \%$ dead cells by Trypan blue exclusion assay $(P=0.003$, Figure 4C) and an addition of $10 \%$ apoptosis cells as shown by Annexin V and PI staining $(P=0.03$, Figure 4D), suggesting a tumor suppressive role of $m i R-3151$ in CLL.

\section{A MSP on Normal Donors}

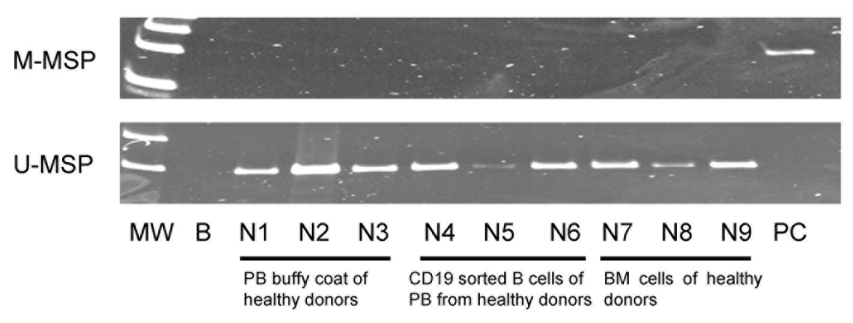

C MSP on CLL cell lines

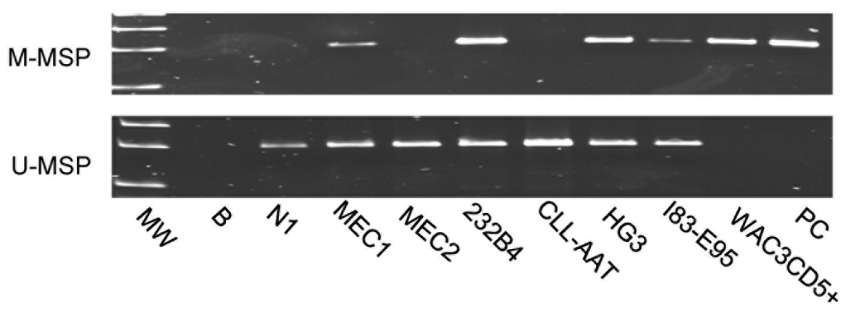

MW: Marker; B: Reagent blank; PC: Positive control with methylated DNA.

\section{Identification of PIK3R2 and MADD as direct targets of $m i R-3151$}

To further understand the mechanism by which $m i R-3151$ regulates cell proliferation and apoptosis in CLL cells, potential direct targets of $m i R-3151$ were screened using four computational prediction softwares including TargetScan Version 6.2, DIANA-microT v3.0, miRDB and miRanda. Two putative targets, MADD and PIK3R2, with known oncogenic properties were concomitantly predicted by all these four miRNA target prediction algorithms, and hence were further studied.

To confirm $M A D D$ and $P I K 3 R 2$ to be direct targets of $m i R-3151$, wild-type and mutant 3'UTR of MADD and $P I K 3 R 2$ luciferase reporter constructs were generated (Figure 5A). For each of MADD and PIK3R2, the wildtype or mutant luciferase construct was co-transfected with miR-3151 mimic into HeLa cells for 48 hours. As shown in Figure $5 \mathrm{~B}$, as compared with co-transfection of scrambled oligonucleotides control, a $35 \%$ reduction of luciferase

\section{B Direct sequencing of the miR-3151 M-MSP products}

Wild-type: G G G A G G G A G A C T G G G $\underline{\mathrm{C}} \mathrm{G}$ G T G G G G A C $\underline{\mathrm{C}} \mathrm{G} G$ Methy: G G G A G G A G A T T G G $\underline{\underline{\mathrm{C} G}} \mathrm{G} T \mathrm{GG} G A \mathrm{~T} \underline{\mathrm{C} G}$

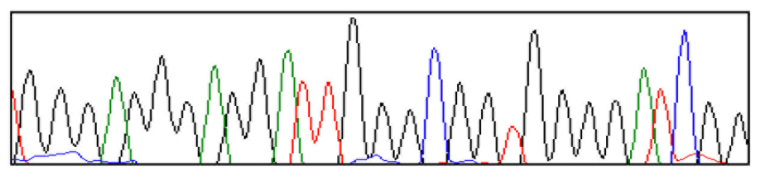

D

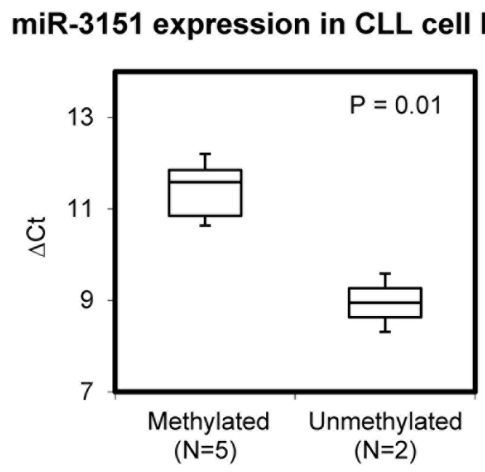

Figure 1: Methylation of $\boldsymbol{m i R}$-3151 in normal donors and cell lines. (A) M-MSP of $m i R$-3151 showed that the positive control (PC) was completely methylated while all 9 normal controls were completely unmethylated. In the U-MSP, the methylated control PC was totally unmethylated, but all normal controls are totally methylated. (B) Sequence analysis of the miR-3151 M-MSP product from bisulfitetreated positive control DNA showed that the cytosine $(\mathrm{C})$ residues of $\mathrm{CpG}$ dinucleotides were methylated and remained unchanged, whereas all the other $\mathrm{C}$ residues were unmethylated and were converted to thymidine [T], suggesting complete bisulfite conversion and specificity of MSP. (C) In 7 CLL cell lines, WAC3CD5+ revealed complete methylation, MEC1, 232B4, HG3 and I83-E95 were partially methylated, while MEC2 and CLL-AAT were completely unmethylated of $m i R-3151$. (D) Stem-loop quantitative RT-PCR analysis of $m i R-3151$ expression in methylated $(N=5)$ versus unmethylated CLL cell lines $(N=2)$. $\Delta \mathrm{Ct}$, Ct miR-3151-Ct RNU48. RNU48 was used as reference of $m i R-3151$ expression by $2^{-\Delta \Delta C T}$ method. 
A MSP on CLL primary samples

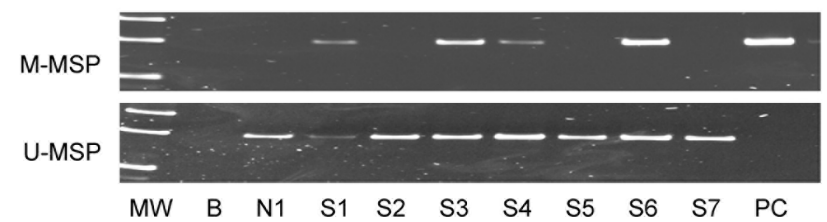

MW: Marker; B: Reagent blank; N1: healthy donor; S: Sample at diagnosis; PC: Positive control with methylated DNA.

B miR-3151 expression in CLL primary samples $(\mathrm{N}=\mathbf{2 0})$

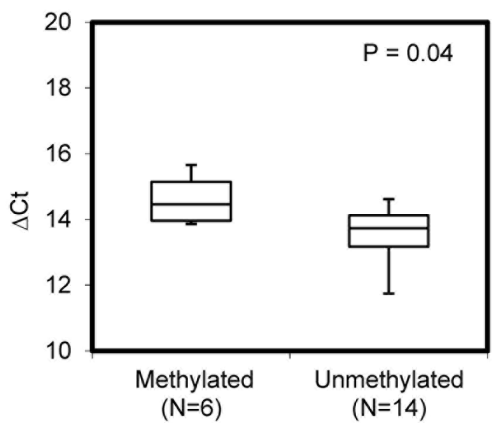

Figure 2: Methylation of $\mathbf{m i R}-3151$ in primary samples. (A) Promoter methylation of miR-3151 in CLL primary samples. (B) Quantitative RT-PCR analysis of $m i R-3151$ expression between miR-3151 methylated primary samples $(N=6)$ and unmethylated samples $(N=14) . \Delta \mathrm{Ct}, \mathrm{Ct}$ miR-3151-Ct RNU48. RNU48 was regarded as internal control. Error bars represent standard deviation.

A 5-AzadC treatment of WAC3CD5+ cells
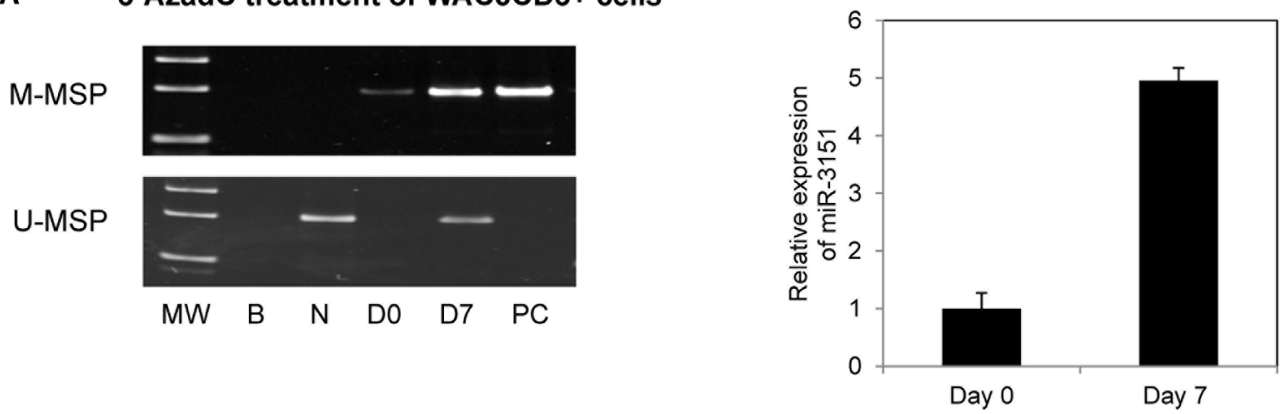

B 5-AzadC treatment of MEC2 cells
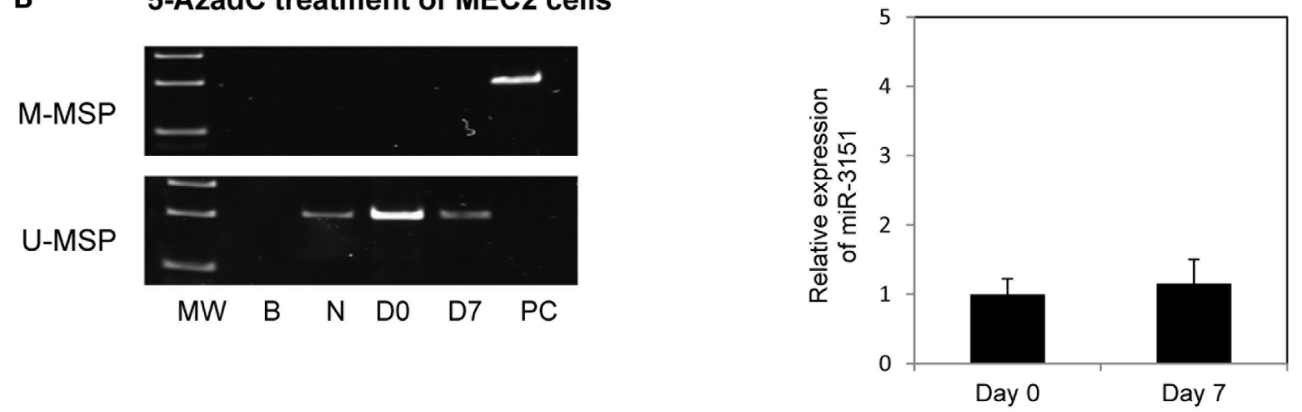

MW: Marker; B: Reagent blank; N: Normal donor; PC: Positive control

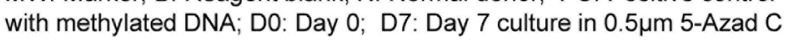

Figure 3: Effect of 5-Aza-2'-deoxycytidine (5-AzadC) treatment on WAC3CD5+ and MEC2 cells. U-/M-MSP of $m i R-3151$ promoter methylation status and stem-loop quantitative RT-PCR analysis of mature miR-3151 expression in (A) WAC3CD5+ cells and (B) MEC2 cells before and after treatment with $0.5 \mu \mathrm{M} 5$-AzadC for 7 days. $\Delta \mathrm{Ct}, \mathrm{Ct} m i R-3151$-Ct RNU48. RNU48 was used as reference for data analysis of $m i R-3151$ expression by $2^{-\Delta \Delta C T}$ method. 
activity was observed in miR-3151 co-transfected with wild-type $M A D D-3$ 'UTR. This suppression was abolished when miR-3151 was co-transfected with Mut MADD3'UTR (with 4 point mutations in seed region binding site) or Del MADD-3'UTR (with miR-3151 binding site deleted). Similarly, as compared with the scrambled oligonucleotides control, over-expression of $m i R-3151$ with wild-type PIK3R2-3'UTR led to a $65 \%$ reduction of luciferase activity. By contrast, the luciferase activity was not suppressed by $m i R-3151$ when 6 point mutations were introduced in each of the three $m i R-3151$ binding sites on the 3'UTR of PIK3R2 (Mut PIK3R2-3'UTR). These findings confirmed that $M A D D$ and $P I K 3 R 2$ are both direct targets of $m i R-3151$. Moreover, in CLL cell lines, whether methylation and hence silencing of $m i R-3151$ correlates with increased expression of $M A D D$ and PIK3R2 was studied by qRT-PCR. Results showed that a trend of methylation was associated with higher expression of the target genes, as indicated by the lower $\Delta \mathrm{Ct}$ (Ct MADD/PIK3R2 - $\mathrm{Ct} G A P D H)$ in methylated cell lines (MM or MU), as compared with those in unmethylated cell lines (UU) (Supplementary Figure S3), confirming the role of methylation of $m i R-3151$ in the regulation of $M A D D$ and PIK3R2 in CLL cells.

\section{miR-3151 overexpression suppresses CLL cell proliferation by directly targeting MADD and PIK3R2 implicated in MEK/ERK and PI3K/ AKT signaling}

miRNAs may affect mRNA stability or translation of target protein-coding genes [21]. To address the biological significance of $m i R-3151$ methylation in CLL cells, we evaluated the mRNA and protein expression of
A

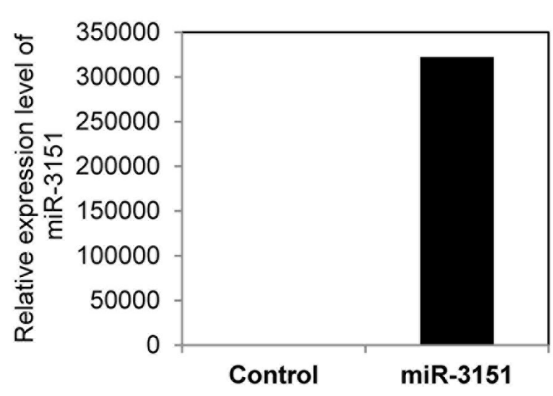

D

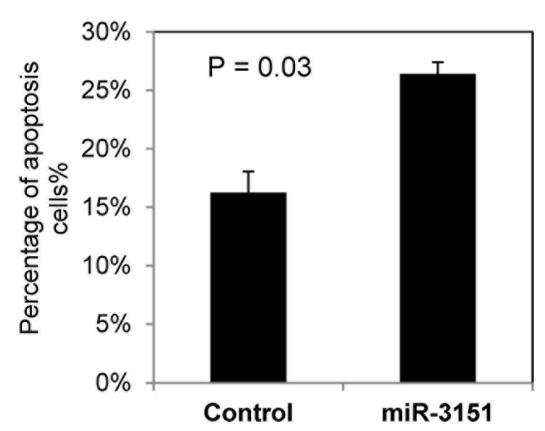

B
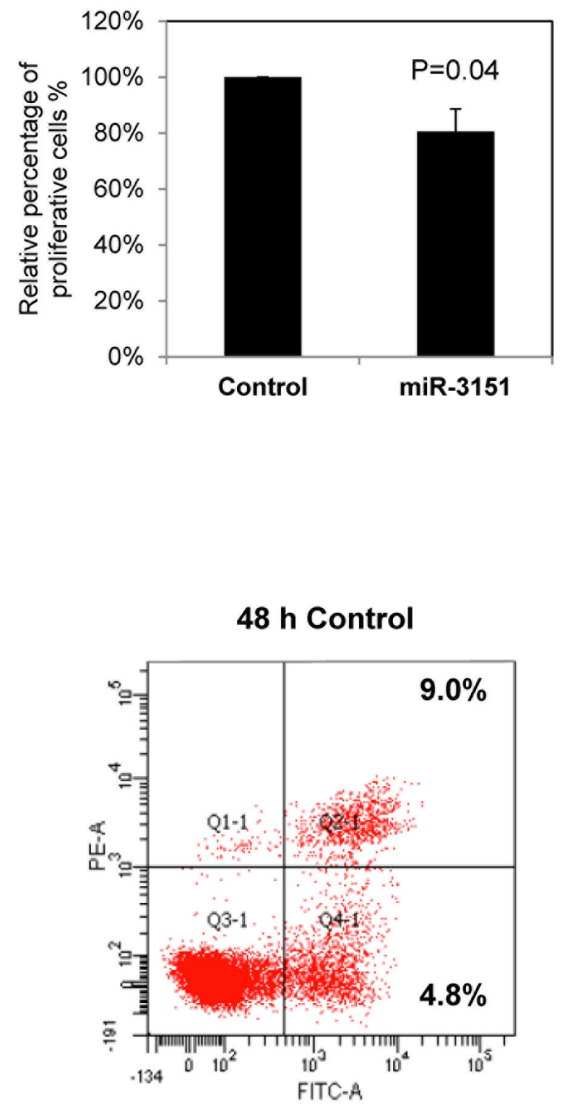

C

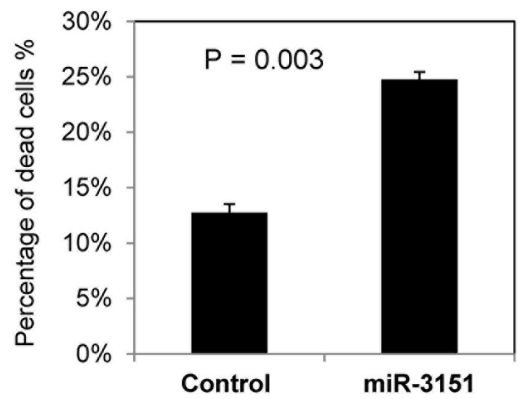

Figure 4: Over-expression of $\mathbf{m i R}-\mathbf{3 1 5 1}$ in CLL cells. WAC3CD5+ cells, completely methylated for miR-3151, were transfected with $m i R-3151$ mimic or scrambled oligonucleotides control. Cells were harvested for functional assays 48 hours after transfection. (A) Stem-loop quantitative RT-PCR analysis of $m i R-3151$ expression at 48 hours after transfection. $\Delta$ Ct, Ct miR-3151-Ct RNU48. RNU48 was chosen as reference using the $2^{-\Delta \Delta C T}$ method. (B) Relative cell proliferation of CLL cells upon over-expression of miR-3151 was measured by MTT assay. Column, mean percentage of cell proliferation from three experiments conducted in triplicate. (C) Percentage of dead cells was measured by Trypan blue exclusion assay. Column, mean percentage of cell death from three experiments with triplicate in each. (D) The percentage of apoptotic CLL cells after miR-3151 transfection was assessed by flow cytometry using FITC Annexin V-PI staining. Left panel: represented average percentage of apoptotic cells from three independent experiments. Right panel: representative results. Error bars represent standard deviation. 
its target genes by qRT-PCR and Western blot respectively after over-expression of miR-3151 in WAC3CD5+ cells with complete miR-3151 methylation. Upon miR-3151 over-expression, MADD and PIK3R2 mRNA levels were significantly downregulated by $34 \%(P=0.02)$ and $28 \%$ $(P=0.04)$ respectively (Figure 6A).

Moreover, at the protein level, restoration of $m i R-3151$ in completely methylated cells resulted in $66 \%$ downregulation of MADD protein, in association with $77 \%$ repression of the downstream phospho-ERK $1 / 2$ protein, indicating that $m i R-3151$ may function as a tumor suppressor by inhibiting MADD/MEK/ERK signaling (Figure 6B). Furthermore, miR-3151 over-expression also led to the $58 \%$ downregulation of PIK3R2 protein, which was associated with a $75 \%$ reduction of the downstream
phospho-AKT (Thr308) protein but not phospho-AKT (Ser473), showing that miR-3151 methylation/silencing accounted for constitutive PIK3R2/PI3K/AKT activation in CLL (Figure 6B). Finally, MCL1 is an important antiapoptotic protein upregulated by ERK or AKT signaling in many cancers including CLL. As shown in Figure 6B, MCL1 protein expression was repressed by $65 \%$ upon $m i R-3151$ over-expression, thereby testifying the tumor suppressor function of $m i R-3151$ in CLL. The average of quantitative densitometry of the relative protein expression (including MADD, PIK3R2, P-ERK1/2, P-AKT (Thr308), P-AKT (Ser473) and MCL1) from two independent experiments were plotted as shown in Figure 6C.

To further confirm the role of PIK3R2 and $M A D D$ in $m i R-3151$-mediated tumor suppression in

\section{A MADD}
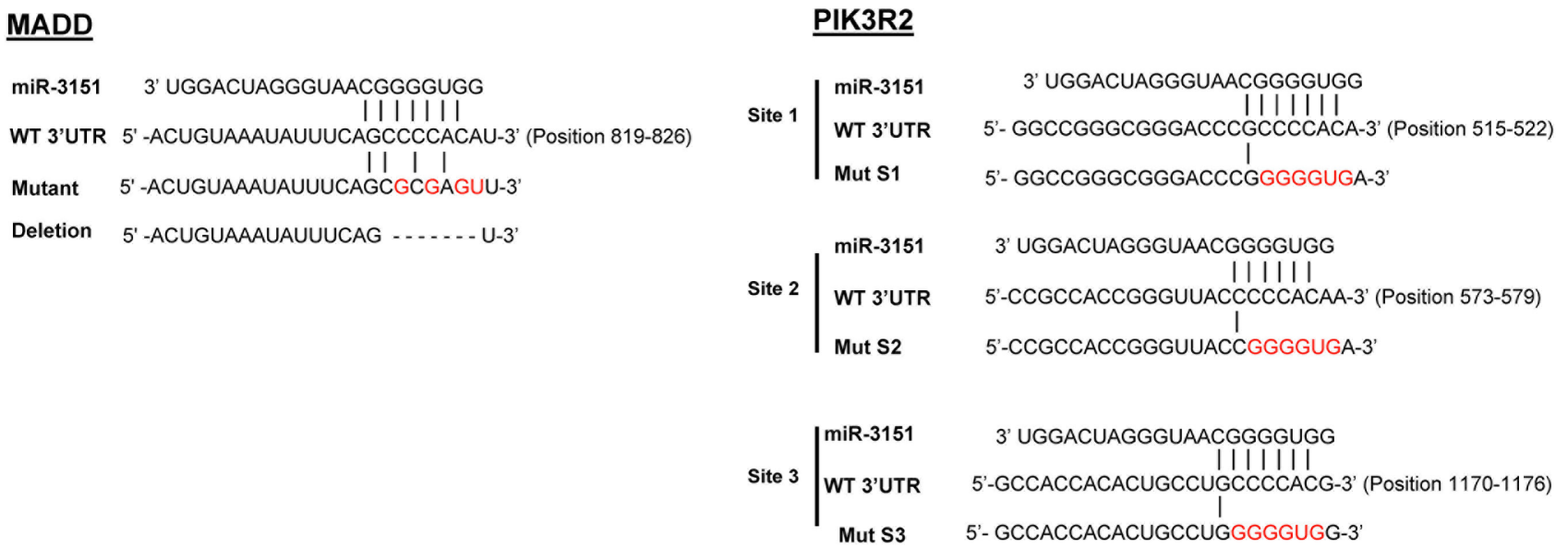

B
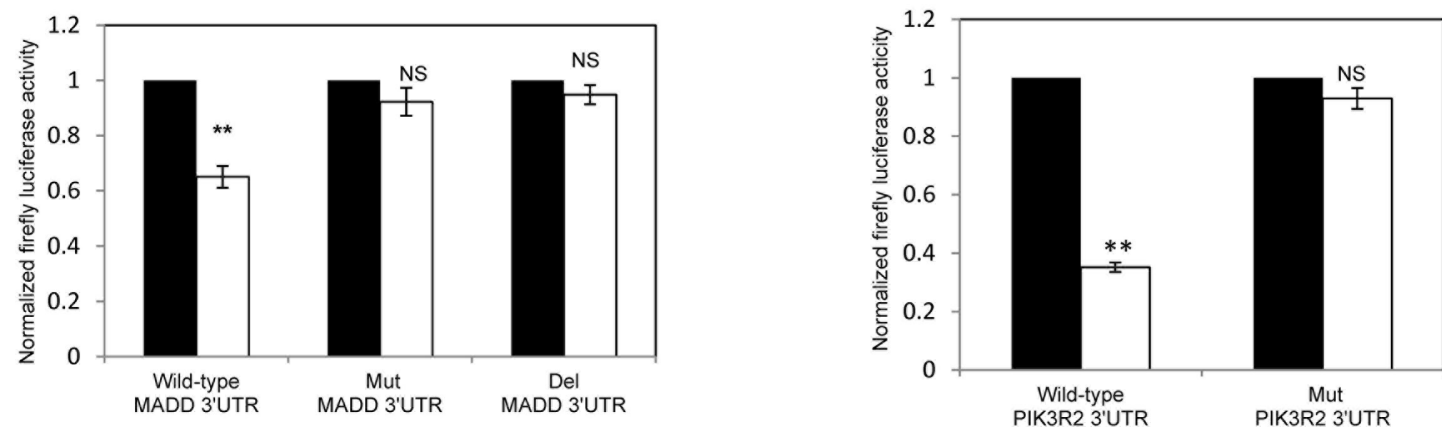

- Control

口miR-3151

**P $<0.001$

NS $=$ Not significant

Figure 5: Identification of direct targets MADD and PIK3R2 for miR-3151. (A) Sequence complementarity of potential $m i R-3151$ binding sites in MADD-3'UTR and PIK3R2-3'UTR. 3'UTR of MADD includes one putative miR-3151 binding site while 3'UTR of $P I K 3 R 2$ is composed of three putative miR-3151 binding sites (S1-S3). Corresponding mutant 3'UTR are shown below. The mutated nucleotides in the $3^{\prime} \mathrm{UTR}$ of MADD or PIK3R2 are indicated in red. Dash line, deletion region in $3^{\prime} \mathrm{UTR}$. (B) Luciferase constructs carrying wild-type or mutant 3'UTR of target gene (MADD or PIK3R2) was co-transfected with miR-3151 as compared with scrambled oligonucleotides control in HeLa cells for 48 hours. Mut PIK3R2-3'UTR contained a three mutated sites, namely Mut S1, Mut S2 and Mut S3, simultaneously. Del MADD-3'UTR was deleted the binding site sequence (5'-CCCCACA-3'). Firefly luciferase activity was normalized to the Renilla lucifrease activity. Column, mean of normalized luciferase activity in triplicates after three independent transfections. Error bar represents standard deviation. 
A

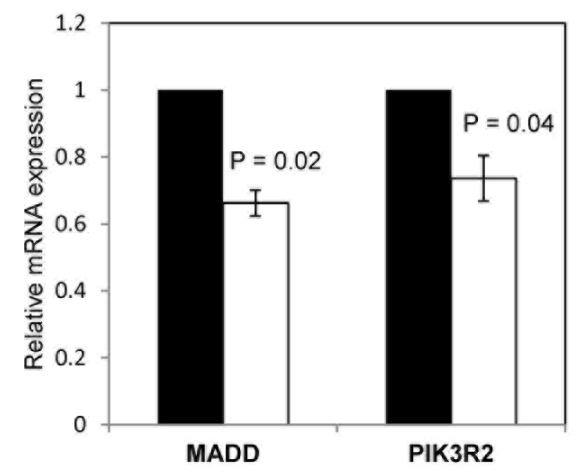

B

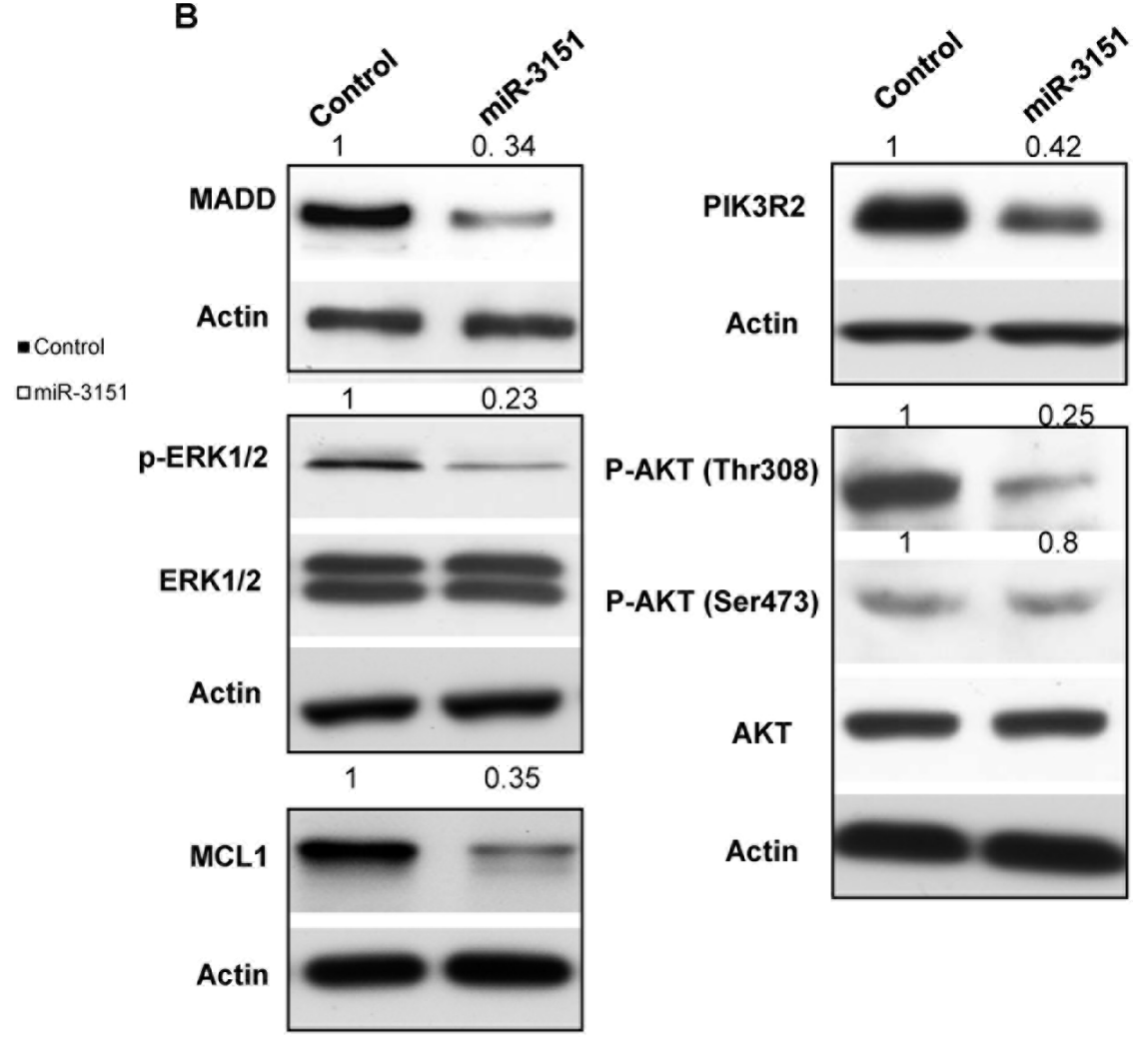

C

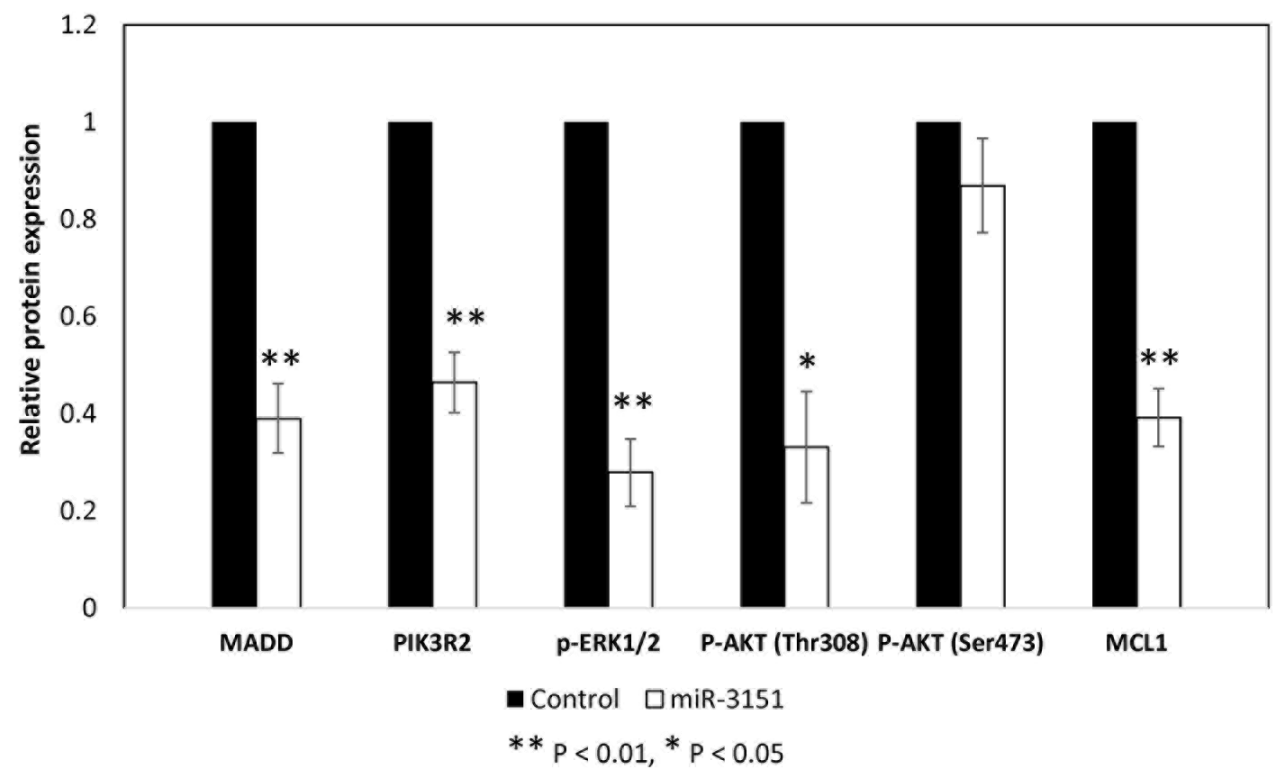

Figure 6: $m i R$-3151 regulates the MEK/ERK and PI3K/AKT signaling by repressing MADD and PIK3R2 respectively. (A) MADD and PIK3R 2 mRNA expression was downregulated upon $m i R-3151$ transfection in WAC3CD5+ cells as compared to scrambled oligonucleotides control. $\triangle \mathrm{Ct}$, $\mathrm{Ct} M A D D / P I K 3 R 2-\mathrm{Ct} \mathrm{GAPDH}$. GAPDH was used as reference for data analysis of MADD/PIK3R2 expression by $2^{-\triangle \triangle C T}$ method. Error bars represent standard deviation. (B) Western analysis showed a decrease of MADD and PIK3R2 protein by introduction of miR-3151 mimic in WAC3CD5+ cells, followed by the reduced p-ERK1/2, P-AKT (Thr308) and MCL1 protein, instead of P-AKT (Ser473). Total levels of ERK1/2 and AKT were not affected. For MADD, PIK3R2 and MCL1, Actin was regarded as the endogenous normalizer and densitometric analysis of normalized protein levels are indicated above the western blot. (C) Two independent transfection were performed. Columns represent the average of quantitative densitometry of the relative protein expression (including MADD, PIK3R2, P-ERK1/2, P-AKT (Thr308), P-AKT (Ser473) and MCL1) from two independent experiments. Error bars represent standard deviation. 
CLL cells, knockdown of each of PIK3R2 and MADD was performed in WAC3CD5+ cells with complete miR-3151 methylation. Upon successful knockdown of PIK3R2 as shown by reduced levels of both mRNA and protein (Supplementary Figure S4A-B), a 30\% reduction of cell proliferation by MTT assay $(P=0.04)$ (Supplementary Figure S4C) and a 13\% increase of dead cells measured by Trypan blue exclusion assay $(P<0.01)$ were demonstrated (Supplementary Figure S4D), as compared with control siRNA. Similarly, knockdown of $M A D D$ in WAC3CD5+ cells (Supplementary Figure S5A-B) showed $20 \%$ decreased cellular proliferation by MTT assay $(P=0.01)$ (Supplementary Figure S5C) and $13 \%$ increased cell death by Trypan blue exclusion assay $(P<0.01)$ (Supplementary Figure S5D). Collectively, these data confirmed that the tumor suppressor function of miR-3151 was mediated via downregulation of PIK3R2 and $M A D D$ (Figure 6).

\section{DISCUSSION}

A few observations were made in this study. Firstly, we demonstrated the tumor-specific methylation of miR-3151 in CLL as evidenced by frequent methylation in CLL cell lines and primary samples but not normal controls, including CD19-sorted normal B-cells. By contrast, $m i R-9-2$ and $m i R-373$ are methylated in both tumor cells and the corresponding normal counterparts, indicating a tissue-specific and not tumor-specific methylation pattern $[17,22]$.

Secondly, DNA methylation of miR-3151 was associated with reversible gene silencing. This was supported by, first, an inverse correlation between methylation status and expression of $m i R-3151$ in cell lines and primary CLL cells. Moreover, hypomethylation treatment of WAC3CD5+ cells with 5-AzadC, which was completely methylated of $m i R-3151$, led to demethylation and re-expression of $m i R-3151$.

Thirdly, we showed that miR-3151 is a tumor suppressor miRNA in CLL, in contrast to recent reports that $m i R-3151$ is oncogenic in cytogenetically normal acute myeloid leukemia (AML) [23, 24], in which $m i R-3151$ functioned as the oncogenic driver targeting TP53 [25]. By contrast, herein, miR-3151 is tumor suppressive in CLL as evidenced by decreased cell proliferation and enhanced apoptosis upon over-expression. Similarly, miR-9 has been shown to be tumor suppressive in ovarian cancer and CLL via inhibition of NF- $\kappa \mathrm{B}$ pathway but oncogenic in breast cancer via activation of $\beta$-catenin signaling $[17,26,27]$. Therefore, a miRNA can be oncogenic in one but tumor suppressive in another cancer type.

Fourthly, in vitro activation of BCR signaling by anti-IgM BCR antibodies induced activation of both
MEK/ERK and PI3K/AKT signaling in CLL, thereby protecting CLL cells from apoptosis [4, 28]. Indeed, by luciferase assays, MADD and PIK3R2 have been validated as direct novel targets of $m i R-3151$. MADD, a splice variant of IG20 (insulinoma-glucagonoma 20) overexpressed in cancer cells [29], is crucial for RAS/ $\mathrm{MEK} / \mathrm{ERK}$ activation by facilitating recruitment of Grb2 to the receptor-mediated signaling complex [30]. On the other hand, PIK3R2 is a subunit of a protein complex for activation of PI3K signaling, which comprises $\mathrm{p} 85$ (p85 $\alpha$ and p85 $\beta$ [alias PIK3R2]) and a p110 catalytic subunit $(\alpha, \beta, \gamma)$ [31]. Indeed, the oncogenic role of PIK3R2 has been demonstrated in breast and colon cancer, in which over-expression of PIK3R2 with concomitant AKT activation correlated with tumor progression in vivo [32].

Herein, over-expression of miR-3151 promoted apoptosis of CLL cells via repression of MADD and p-ERK1/2, and hence inhibition of MADD/RAS/ERK signaling. On the other hand, functional activation of AKT is dependent on the phosphorylation of two residues, Ser473 in the hydrophobic motif or Thr308 in the activation loop [33]. Recently, Thr308 phosphorylation has been found a better biomarker than Ser473 phosphorylation for AKT activation [34]. Similarly, our data showed that the over-expression of $m i R-3151$ enhanced apoptosis of CLL cells through suppression of $\mathrm{PI} 3 \mathrm{~K} / \mathrm{AKT}$ pathway by repressing PIK3R2, which was associated with profound downregulation of Thr308 but not Ser473 phosphorylation. Therefore, activation of PI3K signaling associated with $m i R-3151$-methylation in CLL is mediated by Thr308 but not Ser473 phosphorylation.

In cancer, both ERK and AKT signaling confer resistance to apoptosis via upregulation of a panel of anti-apoptotic proteins including MCL1, X-linked inhibitor of apoptosis protein (XIAP) and BCL-xL. MCL1 has been shown to inhibit apoptosis in CLL [35-37]. Indeed, restoration of $m i R-3151$ mimic in CLL cells resulted in repression of MCL1 protein. Taken together, our data suggested that miR-3151 methylation led to constitutive ERK and AKT activation, and hence over-expression of MCL1, thereby protecting CLL cells from apoptosis.

Last but not least, methylation of $m i R-3151$ (chr. 8q22.3) was associated with that of $m i R-203$ (chr 14q32) and $m i R-34 b / c$ (chr 11q23), which are localized to different chromosomal regions. $m i R-34 b / c$ and miR-203 have also been shown to target CREB independently, and hence methylation of these miRNAs may render upregulation of multiple oncogenes including BCL2 and NF-кB1 [38, 39]. Therefore, these four tumor suppressor miRNAs undergoing methylation may collaborate to confer proliferation advantages to CLL cells.

In conclusion, our results showed that miR-3151 was a tumor suppressor miRNA frequently methylated 
and hence silenced in CLL. Methylation of miR-3151 in CLL cells conferred resistance to apoptosis through over-expression of its direct targets MADD and PIK3R2, and hence constitutive activation of RAS/MEK/ERK and $\mathrm{PI} 3 \mathrm{~K} / \mathrm{AKT}$, and consequently over-expression of MCL1 (Figure 7).

\section{Model of miR-3151 function in CLL cells}

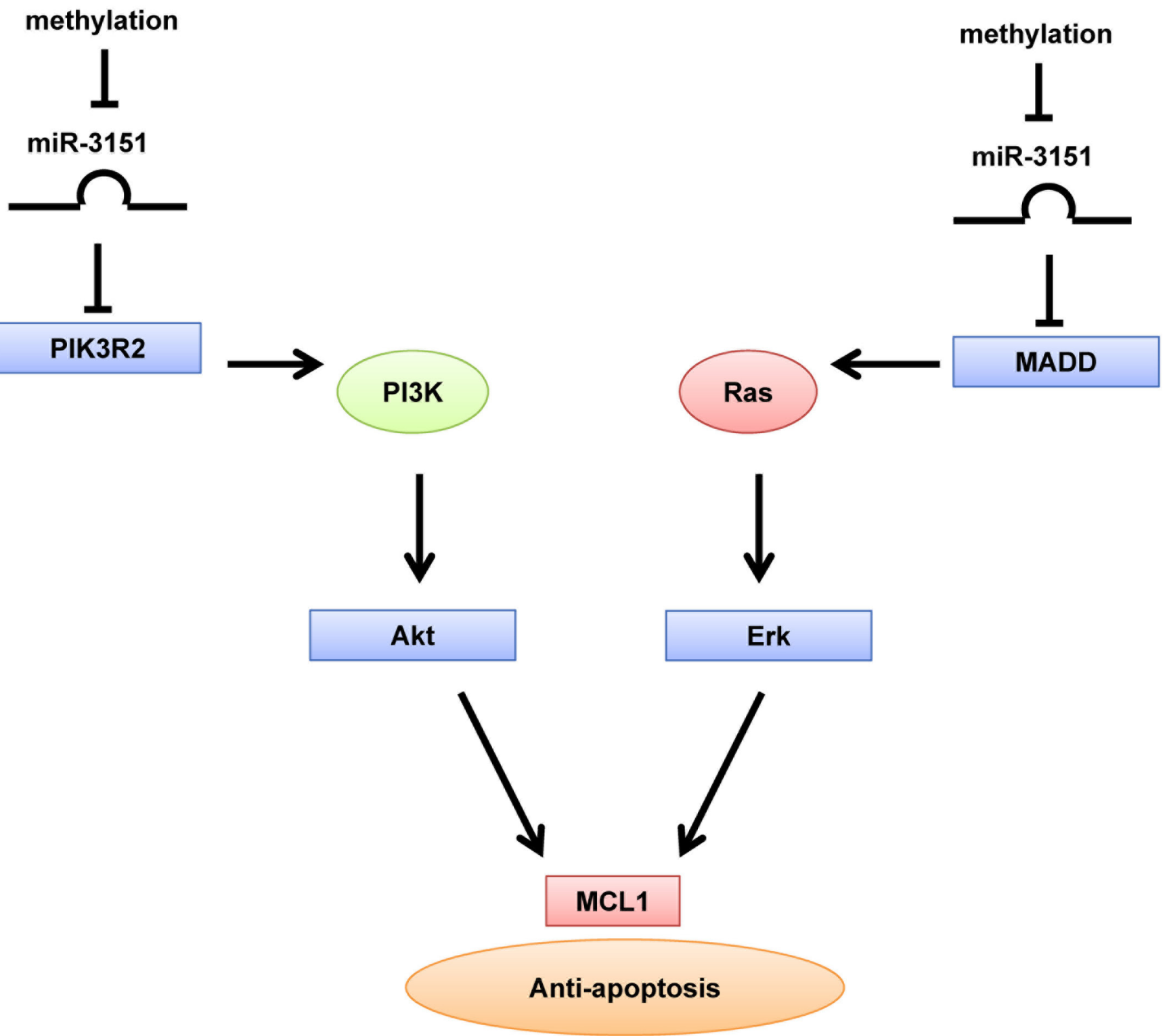

Figure 7: Model of $\boldsymbol{m i R}-3151$ function in CLL cells. Over-expression of $m i R-3151$ represses PIK3R2 and MADD, which further downregulate the PI3K/AKT and MEK/ERK signaling respectively. Thus, miR-3151 methylation protected CLL cells from apoptosis through over-expression of direct targets PIK3R2 and MADD, leading to constitutive activation of PI3K/AKT and MEK/ERK signaling respectively, with consequent upregulation of MCL1. 


\section{MATERIALS AND METHODS}

\section{Patient samples}

Bone marrow samples were collected from 98 Chinese CLL patients diagnosed according to the standard morphologic and immunophenotyping criteria as previously $[17,40]$. Patient demographics were listed in Table 1. The median overall survival (OS) of this cohort was 89 months. The median OS of those with advanced Rai stage and limited Rai stage were 57 and 111 months respectively $(P=0.006)$. Moreover, the median OS for those with or without high/intermediaterisk karyotype were 43 months and 111 months respectively $(P=0.04)$. Of these, the $m i R-203(N=50)$, $m i R-34 b / c(N=78)$ and $m i R-34 a(N=78)$ methylation results have been reported previously $[16,18]$. This study was approved by the Institutional Review Board of Queen Mary Hospital and samples were collected with written informed consent and in accordance with the Declaration of Helsinki.

\section{Cell lines and culture}

The human CLL cell lines MEC1 and CLLAAT were purchased from Deutsche Sammlung von Mikroorganismen und Zellkulturen Deutsche $\mathrm{GmbH}$ (DSMZ) (Braunschweig, Germany) and American Type Culture Collection (ATCC) (Manassas, USA) respectively. MEC2 [41], I83-E95 [42] and WAC3CD5+ [42] were kind gifts from Dr John C. Byrd, Department of Medicine, Ohio State University. HG3 and 232B4 were previously established by Prof. Anders Rosén, Department of Clinical \& Experimental Medicine, Linköping University $[43,44]$. Cell lines were cultured in 90\% RPMI $1640+10 \% \mathrm{FBS}$, supplemented with $50 \mathrm{U} / \mathrm{ml}$ penicillin and $50 \mu \mathrm{g} / \mathrm{ml}$ streptomycin (Invitrogen, Carlsbad, CA, USA) in a humidified atmosphere of $5 \% \mathrm{CO}_{2}$ at $37^{\circ} \mathrm{C}$.

\section{Methylation-specific polymerase chain reaction (MSP)}

DNA was extracted from 98 primary samples, 7 cell lines and 9 normal controls (peripheral blood buffy coats from healthy donors, $N=3$; CD19 sorted peripheral blood B cells from healthy donors, $N=3$; and bone marrow buffy coats from healthy donors, $N=3$ ) using the QIAamp DNA Blood Mini Kit (QIAGEN, Germany) and then were treated with bisulfite to convert unmethylated cytosine to uracil (but unaffecting methylated cytosine) by the EpiTect Bisulfite Kit kit (QIAGEN, Hilden, Germany). For each bisulfite-treated sample, two sets of primers were used to amplify the methylated DNA (methylated-MSP, M-MSP) and unmethylated DNA (unmethylated-MSP, U-MSP) respectively. Primers and conditions for M-MSP and U-MSP of $m i R-3151$ were listed in Table 2.

\section{Quantitative bisulfite pyrosequencing}

Primers for pyrosequencing were used for the amplification of $m i R-3151$ promoter region, which was overlapped with the amplicon of MSP. Primers were designed by PSQ Assay Design software (Biotage). Bisulfite-treated DNA was amplified by PCR with a forward primer (5'-ATGGATAGATGGGTTAGAGATTG-3') and a biotinylated reverse primer (5'-AATAAACCAAATAAATTCTATCTCC-3')

in the following condition: $2 \mathrm{mM} / 59^{\circ} \mathrm{C} / 50 \mathrm{X}$. A stretch of DNA with 6 adjacent $\mathrm{CpG}$ dinucleotides was pyrosequenced using sequencing primer: 5'- GAGAGTTTAGGGAGTTTTAGTTTT-3'. Bisulfitetreated DNA $(2 \mu \mathrm{l})$ was used as template in a PCR reaction with final volume of $50 \mu$ l. The PCR products were purified and loaded onto $6 \%$ non-denaturing polyacrylamide gels with a mass ladder (Fermentas) and stained with ethidium bromide staining for sizing and quantification. Biotinlabeled PCR fragments (5 pmoles) of each sample were subjected to pyrosequencing using the PSQ96MA System (Biotage) and analyzed using PyroQ-CpG 1.0.9, according to manufacturer's instructions.

\section{5-Aza-2'-deoxycytidine (5-AzadC) treatment}

Each of WAC3CD5+ and MEC2 cells at log-phase was cultured in six-well plates at a density of $10^{6}$ cells $/ \mathrm{ml}$, with $0.5 \mu \mathrm{M}$ of 5 -AzadC (Sigma-Aldrich, St. Louis, MO, USA) for 7 days. Fresh 5-AzadC was replaced every 24 hours. Cells of 5-AzadC treatment on day 0 and day 7 were harvested.

\section{Quantification of miR-3151, BAALC, MADD and PIK3R2}

Total RNA was extracted by the mirVana miRNA Isolation Kit (Ambion, Austin, TX, USA). miR-3151 was quantified by the TaqMan MicroRNA RT Kit and TaqMan MicroRNA Assay Kit (ABI, Foster City, CA, USA) with RNU48 as reference. BAALC was quantified by $B A A L C$ Taqman Gene Expression Assay (Cat. 4351372) (ABI, Foster City, CA, USA), according to the manufacturer's instructions. For MADD and PIK3R2, total RNA was reverse transcribed by the QuantiTect Reverse Transcription Kit (QIAGEN, Valencia, CA), and quantified using SYBR Green Master Mix (ABI, Foster City, CA, USA), following the manufacturer's instructions. $G A P D H$ was used as endogenous control for data analysis of BAALC, MADD and PIK3R2 [45]. The $2^{-\triangle A C T}$ method was used to detect the expression of $m i R-3151$ and target genes (MADD and PIK3R2) before and after over-expression of $m i R-3151$ in WAC3CD5+ cells; and the expression of $m i R-3151$ before and after 5-AzadC treatment [45]. For comparing the miR-3151 and target genes (MADD and PIK3R2) expression between 
Table 1: The CLL patients demographics $(N=98)$

\begin{tabular}{|c|c|}
\hline Characteristic & Value \\
\hline Gender $(\mathrm{M} / \mathrm{F})$ & $67(68.4 \%) / 31(31.6 \%)$ \\
\hline Median age (range)-yr & $67(37-91)$ \\
\hline Rai stage $(\leq \mathrm{II} />\mathrm{II})^{*}$ & $56(62.2 \%) / 34(37.8 \%)$ \\
\hline Median lymphocyte count (range) & $16 \times 10^{9} / \mathrm{L}\left(10-540 \times 10^{9} / \mathrm{L}\right)$ \\
\hline \multicolumn{2}{|l|}{ High-risk cytogenetics } \\
\hline $\operatorname{del}(17 p)$ & $3(4.8 \%)$ \\
\hline $\operatorname{del}(11 q)$ & $2(3.2 \%)$ \\
\hline trisomy 12 & $11(17.5 \%)$ \\
\hline \multicolumn{2}{|l|}{ Low-risk cytogenetics ${ }^{\ddagger}$} \\
\hline $\operatorname{del}(13)$ & $19(30.2 \%)$ \\
\hline normal karyotype & $21(33.3 \%)$ \\
\hline other karyotype abnormalities & $7(11.0 \%)$ \\
\hline
\end{tabular}

*from 90 patients with clinical data; ${ }^{\star}$ from 63 patients with cytogenetic data.

Table 2: miR-3151 MSP Primer sequences and condition

\begin{tabular}{|l|l|l|c|}
\hline \multicolumn{1}{c}{$\boldsymbol{m i R}-\mathbf{3 1 5 1}$} & \multicolumn{1}{l}{ Forward primer $\left(\mathbf{5}^{\prime}\right.$ ' to $\left.\mathbf{3}^{\prime}\right)$} & \multicolumn{1}{c}{ Reverse primer $\left(\mathbf{5}^{\prime}\right.$ to $\left.\mathbf{3}^{\prime}\right)$} & $\mathbf{T m} / \mathbf{c y c l e s} / \mathbf{M g C l}_{\mathbf{2}}$ \\
\hline U-MSP & GTTTTTGTTTTGGGTTGTTAT & AAAACTCCTACAATACCCA & $56^{\circ} \mathrm{C} / 35 \times / 2 \mathrm{mM}$ \\
\hline M-MSP & GTTTTTGTTTTCGGGTCGTTAC & CGAAACTCCTACGATACCCG & $55^{\circ} \mathrm{C} / 35 \times / 1.5 \mathrm{mM}$ \\
\hline
\end{tabular}

Abbreviations: M-MSP, MSP for the methylated allele; U-MSP, MSP for the unmethylated allele; Tm, annealing temperature.

methylated and unmethylated CLL cell lines or primary samples, $\triangle \mathrm{CT}$ method is used. Primers for detecting the mRNA expression of $M A D D$ and PIK3R2 were summarized in Supplementary Table S1.

\section{Transfection of miR-3151}

Either precursor $m i R-3151$ mimic (final concentration $100 \mathrm{nM}$ ) (Ambion, Austin, TX, USA) or scrambled oligonucleotides control (negative control) was transfected into $1 \times 10^{6}$ WAC3CD5+ cells at log phase using X-tremeGENE siRNA Transfection Reagent (Roche, Basel, Switzerland), according to the manufacturers' instructions.

\section{Silencing of $P I K 3 R 2$ and $M A D D$ by RNA interference}

RNA interference by small interfering RNA (siRNA) was used to knockdown the expression of PIK3R2 and $M A D D$ in WAC3CD5+ cells. For knockdown of PIK3R2, cells were plated at a density of $1 \times 10^{6} / \mathrm{ml}$ in a sixwell plate and transfected with $120 \mathrm{nM}$ PIK3R2 siRNA (top strand: 5'-GCGGGAACAAUAAGCUGAUTT-3') or control siRNA (GenePharma Biotechnology, Shanghai, China) using Lipofectamine 2000 (Invitrogen) according to the manufacturer's instructions. Cells were cultured and analyzed at 72 hours after transfection. For knockdown of $M A D D$, cells were transfected with 100nM MADD siRNA (Santa Cruz Biotechnology, sc-75726) or control siRNA-A (Santa Cruz Biotechnology, sc-37007) and analyzed at 48 hours after transfection. The efficiency of siRNA was determined by qRT-PCR and Western blot.

\section{Cell proliferation and viability assays}

MTT assay was used to determine the cellular proliferation by colorimetric quantification of purple formazan formed from the reduction of yellow tetrazolium MTT (3-(4, 5-dimethylthiazolyl-2)-2, 5 -diphenyltetrazolium bromide) by proliferative viable cells [46]. Cells were seeded in a 96-well microtitre plate at $2 \times 10^{5}$ cells/well in $100 \mu \mathrm{l}$ of medium. Forty-eight hours after transfection, each well was added $10 \mu \mathrm{l}$ of $5 \mathrm{mg} / \mathrm{ml} \mathrm{MTT} \mathrm{reagent} \mathrm{(Sigma-Aldrich)} \mathrm{and} \mathrm{incubated}$ 
for 5 hours, followed by adding $100 \mu$ dimethyl sulfoxide (DMSO). Then the absorbance at $550 \mathrm{~nm}$ with reference to $650 \mathrm{~nm}$ was measured. Cell viability was analyzed by Trypan blue dye exclusion assay under microscope and five random microscopic fields were counted for each sample. Dead cells $(\%)=($ total number of dead cells per microscopic field / total number of cells per microscopic field) $\times 100$. MTT assay and Trypan blue dye exclusion assay were performed in triplicate in each of the three independent transfections.

\section{Cell apoptosis assay}

Cellular apoptosis was verified by flow cytometry using FITC Annexin V Apoptosis Detection Kit I (BD-Pharmingen) as described before [17, 47]. The presence of cells with FITC Annexin V positive, propidium iodide (PI) negative (early apoptosis) or FITC Annexin V positive, PI positive cells (late apoptosis) suggests apoptosis. FACS analyses were performed by a flow cytometer (FACSCanto II) equipped with FACSDiva V6.1.2 software (BD Biosciences). Data were derived from three independent transfections.

\section{Plasmid constructs}

The full-length 3'UTR of $M A D D$ includes one putative $m i R-3151$ binding site (819-826 bp of 3'UTR) while the 3 'UTR of PIK3R2 includes three putative miR-3151 binding sites (Site 1, 515-522 bp; Site 2, 573-579 bp; Site 3, 1170-1176 bp of 3'UTR). The 3'UTR segments of MADD ( 220 bp) and PIK3R2 ( $\sim 750 \mathrm{bp}$ ) containing putative $m i R-3151$ binding sites were respectively amplified and cloned into the NheI and SalI sites of a dual firefly/renilla luciferase reporter vector, pmirGLO (Promega, Madison, WI, USA). Two different types of $M A D D-3$ 'UTR mutants were constructed using the QuikChange Lightning Site-Directed Mutagenesis Kit (Stratagene, La Jolla, CA, USA), one with 4 point mutations introduced in the seed region binding site (Mut MADD-3'UTR) while the other with the entire seed region binding site (5'-CCCCACA-3') deleted (Del MADD-3'UTR). For PIK3R2-3'UTR mutant (Mut PIK3R2-3'UTR), six point mutations were introduced to each of the three binding sites by mutagenesis using QuikChange Lightning Multi Site-Directed Mutagenesis Kit (Stratagene, La Jolla, CA, USA). The primers for wildtype and mutant $M A D D / P I K 3 R 2-3$ 'UTR constructs above were summarized in Supplementary Table S1. Wild-type and mutant inserts were confirmed by sequencing shown in Supplementary Figure S6.

\section{Luciferase reporter assay}

Luciferase reporter vector pmirGLO (Wild-type or mutant $M A D D / P I K 3 R 2-3^{\prime} \mathrm{UTR}, 1 \mu \mathrm{g}$ ) was co-transfected with either precursor $m i R-3151$ mimic (final concentration $50 \mathrm{nM}$ ) or scrambled oligonucleotides control (final concentration $50 \mathrm{nM}$ ) into HeLa cells (kind gift from Dr Zou, Department of Medicine, The University of Hong Kong) using Lipofectamine 2000 (Invitrogen). After 48 hours transfection, the luminescent signal was generated and analyzed by Dual-Luciferase Reporter Assay System (Promega), according to the manufacturers' instructions [39]. Firefly luciferase activity was normalized to the Renilla luciferase activity. Data represents the mean normalized luciferase activity derived from three independent transfections with triplicate in each.

\section{Western Blotting}

Western Blots were performed with $20 \mu \mathrm{g}$ protein from each sample. After 48 hours transfection, WAC3CD5+ cells were harvested and lysed in RIPA buffer (50 mM Tris-HCl, pH 7.4, $150 \mathrm{mM} \mathrm{NaCl}, 0.2 \%$ SDS, 1\% Triton X-100, 2 mM EDTA). Protein lysates were separated on $10 \%$ SDS-PAGE and blotted onto a $0.2 \mu \mathrm{m}$ nitrocellulose membrane (Bio-Rad, Hercules, CA). The primary antibodies used were for antiMADD (1:2000; Abcam), -PIK3R2 (1:1000; Abcam), -phospho-p44/42 MAPK (ERK1/2) (Thr202/Tyr204) (1:1000; Cell Signaling), -p44/42 MAPK (ERK1/2) (1:1000; Cell Signaling), -phospho-Akt (Thr308) (1:2000; Cell Signaling), -phospho-AKT (Ser473) (1:2000; Cell Signaling), -AKT (1:1000; Cell Signaling) and anti-actin (1:5000; Sigma-Aldrich, USA) at $4^{\circ} \mathrm{C}$ overnight. Then membranes were washed and incubated with anti-rabbit or anti-mouse horseradish peroxidase conjugate secondary antibody at room temperature for 1 hour. ECL plus Western blotting detection reagent was used for the detection of protein signals with X-ray film (Amersham Biosciences, Buckinghamshire, UK). Protein bands were quantified using densitometry as measured by Quantity One 4.6.2 software (Bio-Rad); hence relative protein expression was expressed in comparison to corresponding control.

\section{Statistical analysis}

In 98 primary CLL samples, the correlation between miR-3151 methylation with continuous (mean age, mean lymphocyte counts, diagnostic hemoglobin or platelet counts) and categorical variables (gender, Rai stage or high-risk karyotypes) were analyzed by student's t-test and chi-square test (or Fisher's exact test) respectively. OS is measured from the date of diagnosis to the date of last follow-up or death. Survival was plotted by the Kaplan-Meier method and compared by the log-rank test. OS of CLL patients with limited Rai stage (stage 0/I/II) was compared with those with advanced Rai stage (stage III/IV). Moreover, OS of CLL patients with high-risk karyotypes [del(17p), del(11q) or trisomy 12] 
was compared to those with standard-risk karyotypes [del(13q), normal karyotype or other karyotypic changes]. Association between methylation of $m i R-3151$ and $m i R-203,-34 b / c$ or $34 a$ was studied by Chi-square test. The mean values of MTT assay, Trypan blue exclusion assay and cell apoptosis assay in WAC3CD5+ cells transfected with precursor miR-3151 mimic (MADD or $P I K 3 R 2$ siRNA) were compared with negative control transfected with a scrambled oligo (control siRNA) by Student's $t$-test. All $P$ values were two-sided.

\section{ACKNOWLEDGMENTS AND FUNDINGS}

We would like to thank Dr John Byrd, Department of Medicine, Ohio State University, USA for the CLL cell lines (MEC2, WAC3CD5+ and I83-E95).

\section{CONFLICTS TO INTEREST}

There are no conflicts to declare.

\section{REFERENCES}

1. Chiorazzi N, Rai KR, Ferrarini M. Chronic lymphocytic leukemia. N Engl J Med. 2005; 352:804-815.

2. Munk Pedersen I, Reed J. Microenvironmental interactions and survival of CLL B-cells. Leuk Lymphoma. 2004; 45:2365-2372.

3. Caligaris-Cappio F, Bertilaccio MTS, Scielzo C. How the microenvironment wires the natural history of chronic lymphocytic leukemia. Semin Cancer Biol. 2014; 24:43-48.

4. Longo PG, Laurenti L, Gobessi S, Sica S, Leone G, Efremov DG. The Akt/Mcl-1 pathway plays a prominent role in mediating antiapoptotic signals downstream of the B-cell receptor in chronic lymphocytic leukemia B cells. Blood. 2008; 111:846-855.

5. Pleyer L, Egle A, Hartmann TN, Greil R. Molecular and cellular mechanisms of CLL: novel therapeutic approaches. Nat Rev Clin Oncol. 2009; 6:405-418.

6. Esteller M. Epigenetics in cancer. N Engl J Med 2008; 358:1148-1159.

7. Oakes CC, Claus R, Gu L, Assenov Y, Hüllein J, Zucknick M, Bieg M, Brocks D, Bogatyrova O, Schmidt CR, Rassenti L, Kipps TJ, Mertens D, Lichter P, Döhner H, Stilgenbauer S, et al. Evolution of DNA Methylation Is Linked to Genetic Aberrations in Chronic Lymphocytic Leukemia. Cancer Discov. 2014; 4:348-361.

8. Khoury JD, Rassidakis GZ, Medeiros LJ, Amin HM, Lai R. Methylation of SHP1 gene and loss of SHP1 protein expression are frequent in systemic anaplastic large cell lymphoma. Blood. 2004; 104:1580-1581.

9. Herman JG, Civin CI, Issa J-PJ, Collector MI, Sharkis SJ, Baylin SB. Distinct patterns of inactivation of p15INK4B and p16INK4A characterize the major types of hematological malignancies. Cancer Res. 1997; 57:837-841.
10. Galm O, Yoshikawa H, Esteller M, Osieka R, Herman JG. SOCS-1, a negative regulator of cytokine signaling, is frequently silenced by methylation in multiple myeloma. Blood. 2003; 101:2784-2788.

11. Chim CS, Pang R, Liang R. Epigenetic dysregulation of the Wnt signalling pathway in chronic lymphocytic leukaemia. J Clin Pathol. 2008; 61:1214-1219.

12. Chim CS, Fung TK, Wong KF, Lau JS, Liang R. Frequent DAP kinase but not p14 or Apaf-1 hypermethylation in B-cell chronic lymphocytic leukemia. J Hum Genet. 2006; 51:832-838.

13. Chen SS, Claus R, Lucas DM, Yu L, Qian J, Ruppert AS, West DA, Williams KE, Johnson AJ, Sablitzky F. Silencing of the inhibitor of DNA binding protein 4 (ID4) contributes to the pathogenesis of mouse and human CLL. Blood. 2011; 117:862-871.

14. Bartel D. MicroRNAs: Genomics, Biogenesis, Mechanism, and Function. Cell. 2004; 116:281-297.

15. Negrini M, Cutrona G, Bassi C, Fabris S, Zagatti B, Colombo M, Ferracin M, D'Abundo L, Saccenti E, Matis S. microRNAome expression in chronic lymphocytic leukemia: comparison with normal B-cell subsets and correlations with prognostic and clinical parameters. Clin Cancer Res. 2014; 20:4141-4153.

16. Chim CS, Wong KY, Leung CY, Chung LP, Hui PK, Chan SY, $\mathrm{Yu}$ L. Epigenetic inactivation of the hsa-miR-203 in haematological malignancies. J Cell Mol Med. 2011; 15:2760-2767.

17. Wang LQ, Kwong YL, Kho CSB, Wong KF, Wong KY, Ferracin M, Calin GA, Chim CS. Epigenetic inactivation of miR-9 family microRNAs in chronic lymphocytic leukemia-implications on constitutive activation of NFkB pathway. Mol Cancer. 2013; 12:173.

18. Wang LQ, Kwong YL, Wong KF, Kho CS, Jin DY, Tse E, Rosèn A, Chim CS. Epigenetic inactivation of mir-34b/c in addition to mir-34a and DAPK1 in chronic lymphocytic leukemia. J Trans1 Med. 2014; 12:52.

19. Wang LQ, Liang R, Chim CS. Methylation of tumor suppressor microRNAs: lessons from lymphoid malignancies. Expert Rev Mol Diagn 2012; 12:10.

20. Berndt SI, Skibola CF, Joseph V, Camp NJ, Nieters A, Wang Z, Cozen W, Monnereau A, Wang SS, Kelly RS. Genome-wide association study identifies multiple risk loci for chronic lymphocytic leukemia. Nat Genet. 2013; 45:868-876.

21. Lujambio A, Lowe SW. The microcosmos of cancer. Nature. 2012; 482:347-355.

22. Lujambio A, Ropero S, Ballestar E, Fraga MF, Cerrato C, Setién F, Casado S, Suarez-Gauthier A, Sanchez-Cespedes M, Gitt A, Spiteri I, Das PP, Caldas C, Miska E, Esteller M. Genetic Unmasking of an Epigenetically Silenced microRNA in Human Cancer Cells. Cancer Res. 2007; 67:1424-1429.

23. Eisfeld A-K, Marcucci G, Maharry K, Schwind S, Radmacher MD, Nicolet D, Becker H, Mrózek K, 
Whitman SP, Metzeler KH. miR-3151 interplays with its host gene BAALC and independently affects outcome of patients with cytogenetically normal acute myeloid leukemia. Blood. 2012; 120:249-258.

24. Diaz-Beya M, Brunet S, Nomdedeu J, Cordeiro A, Tormo M, Escoda L, Ribera JM, Arnan M, Heras I, Gallardo D, Bargay J, Queipo de Llano MP, Salamero O, Marti JM, Sampol A, Pedro C, et al. The expression level of BAALC-associated microRNA miR-3151 is an independent prognostic factor in younger patients with cytogenetic intermediate-risk acute myeloid leukemia. Blood Cancer J. 2015; 5:e352.

25. Eisfeld A-K, Schwind S, Patel R, Huang X, Santhanam R, Walker CJ, Markowitz J, Hoag KW, Jarvinen TM, Leffel B, Perrotti D, Carson WE, III, Marcucci G, Bloomfield CD, de la Chapelle A. Intronic miR-3151 Within BAALC Drives Leukemogenesis by Deregulating the TP53 Pathway. Sci Signal. 2014; 7:ra36.

26. Ma L, Young J, Prabhala H, Pan E, Mestdagh P, Muth D, Teruya-Feldstein J, Reinhardt F, Onder TT, Valastyan S. miR-9, a MYC/MYCN-activated microRNA, regulates E-cadherin and cancer metastasis. Nat Cell Biol. 2010; 12:247-256.

27. Guo LM, Pu Y, Han Z, Liu T, Li YX, Liu M, Li X, Tang H. MicroRNA-9 inhibits ovarian cancer cell growth through regulation of NF-kB1. FEBS Journal. 2009; 276:5537-5546.

28. Petlickovski A, Laurenti L, Li X, Marietti S, Chiusolo P, Sica S, Leone G, Efremov DG. Sustained signaling through the B-cell receptor induces Mcl-1 and promotes survival of chronic lymphocytic leukemia B cells. Blood. 2005; 105:4820-4827.

29. Al-Zoubi AM, Efimova EV, Kaithamana S, Martinez O, El-Idrissi ME-A, Dogan RE, Prabhakar BS. Contrasting Effects of IG20 and Its Splice Isoforms, MADD and DENN-SV, on Tumor Necrosis Factor $\alpha$-induced Apoptosis and Activation of Caspase-8 and -3. J Biol Chem. 2001; 276:47202-47211.

30. Kurada BRVVSN, Li LC, Mulherkar N, Subramanian M, Prasad KV, Prabhakar BS. MADD, a Splice Variant of IG20, Is Indispensable for MAPK Activation and Protection against Apoptosis upon Tumor Necrosis Factor- $\alpha$ Treatment. J Biol Chem. 2009; 284:13533-13541.

31. Vivanco I, Sawyers CL. The phosphatidylinositol 3-kinaseAKT pathway in human cancer. Nat Rev Cancer. 2002; 2:489-501.

32. Cortés I, Sánchez-Ruíz J, Zuluaga S, Calvanese V, Marqués M, Hernández C, Rivera T, Kremer L, González-García A, Carrera AC. p85 $\beta$ phosphoinositide 3-kinase subunit regulates tumor progression. Proc Natl Acad Sci U S A. 2012; 109:11318-11323.

33. Sarbassov DD, Guertin DA, Ali SM, Sabatini DM. Phosphorylation and regulation of Akt/PKB by the rictormTOR complex. Science. 2005; 307:1098-1101.
34. Vincent E, Elder D, Thomas E, Phillips L, Morgan C, Pawade J, Sohail M, May M, Hetzel M, Tavaré J. Akt phosphorylation on Thr308 but not on Ser473 correlates with Akt protein kinase activity in human non-small cell lung cancer. Br J Cancer. 2011; 104:1755-1761.

35. Wang J-M, Chao J-R, Chen W, Kuo M-L, Yen JJ-Y, Yang-Yen H-F. The antiapoptotic gene mcl-1 is up-regulated by the phosphatidylinositol 3-kinase/Akt signaling pathway through a transcription factor complex containing CREB. Mol Cell Biol. 1999; 19:6195-6206.

36. Booy E, Henson E, Gibson S. Epidermal growth factor regulates Mcl-1 expression through the MAPK-Elk-1 signalling pathway contributing to cell survival in breast cancer. Oncogene. 2011; 30:2367-2378.

37. Pepper C, Lin TT, Pratt G, Hewamana S, Brennan P, Hiller L, Hills R, Ward R, Starczynski J, Austen B. Mcl-1 expression has in vitro and in vivo significance in chronic lymphocytic leukemia and is associated with other poor prognostic markers. Blood. 2008; 112:3807-3817.

38. Pigazzi M, Manara E, Baron E, Basso G. miR-34b Targets Cyclic AMP-Responsive Element Binding Protein in Acute Myeloid Leukemia. Cancer Res. 2009; 69:2471-2478.

39. Wong KY, Liang R, So CC, Jin DY, Costello JF, Chim CS. Epigenetic silencing of MIR203 in multiple myeloma. Br J Haematol. 2011; 154:569-578.

40. Hallek M, Cheson BD, Catovsky D, Caligaris-Cappio F, Dighiero G, Döhner H, Hillmen P, Keating MJ, Montserrat E, Rai KR, Kipps TJ. Guidelines for the diagnosis and treatment of chronic lymphocytic leukemia: a report from the International Workshop on Chronic Lymphocytic Leukemia updating the National Cancer Institute-Working Group 1996 guidelines. Blood. 2008; 111:5446-5456.

41. Stacchini A, Aragno M, Vallario A, Alfarano A, Circosta P, Gottardi D, Faldella A, Rege-Cambrin G, Thunberg U, Nilsson K. MEC1 and MEC2: two new cell lines derived from B-chronic lymphocytic leukaemia in prolymphocytoid transformation. Leuk Res. 1999; 23:127-136.

42. Wendel-Hansen V, Sällström J, De Campos-Lima P, Kjellström G, Sandlund A, Siegbahn A, Carlsson M, Nilsson K, Rosen A. Epstein-Barr virus (EBV) can immortalize B-cll cells activated by cytokines. Leukemia. 1994; 8:476-484.

43. Rosén A, Bergh AC, Gogok P, Evaldsson C, Myhrinder AL, Hellqvist E, Rasul A, Björkholm M, Jansson M, Mansouri L. Lymphoblastoid cell line with B1 cell characteristics established from a chronic lymphocytic leukemia clone by in vitro EBV infection. OncoImmunology. 2012; 1:18-27.

44. Lanemo Myhrinder A, Hellqvist E, Bergh A-C, Jansson M, Nilsson K, Hultman P, Jonasson J, Buhl AM, Bredo Pedersen L, Jurlander J. Molecular characterization of neoplastic, normal "sister" lymphoblastoid B-cell lines from chronic lymphocytic leukemia. Leuk Lymphoma. 2013; 54:1769-1779. 
45. Livak KJ, Schmittgen TD. Analysis of Relative Gene Expression Data Using Real-Time Quantitative PCR and the $2{ }^{\Delta \Delta}$ CT Method. Methods. 2001; 25:402-408.

46. Mosmann T. Rapid colorimetric assay for cellular growth and survival: application to proliferation and cytotoxicity assays. J Immunol Methods. 1983; 65:55-63.
47. van Engeland M, Ramaekers FC, Schutte B, Reutelingsperger CP. A novel assay to measure loss of plasma membrane asymmetry during apoptosis of adherent cells in culture. Cytometry. 1996; 24:131-139. 